\title{
PENGARUH GAYA KEPEMIMPINAN DAN DISIPLIN KERJA TERHADAP KINERJA KARYAWAN
}

\author{
Wanudhyaria Hamarto \\ UniSadhuGuna Business School \\ Witjak.sf@gmail.com
}

\begin{abstract}
Abstrak
Penelitian ini dilakukan di PT Dagsap Endura Eatore yang merupakan perusahaan manufaktur olahan makanan seperti naget, sosis, baso dan daging asap. PT Dagsap Endura Eatore memiliki tujuan untuk meluaskan pasar sampai keseluruh Indonesia. Dalam mencapai tujuannya, maka PT Dagsap Endura Eatore harus bisa meningkatkan kinerja para karyawannya agar dapat bekerja dengan efektif dan efisien. Penelitian ini berlokasi pada PT Dagsap Endura Eatore (PT DEE) kantor cabang Jakarta Selatan. Tujuan penelitian untuk menguji dan menganalisis pengaruh gaya kepemimpinan terhadap kinerja karyawan PT DEE kantor cabang Jakarta Selatan, pengaruh disiplin kerja terhadap kinerja karyawan PT DEE kantor cabang Jakarta Selatan, dan pengaruh keduanya gaya kepemimpinan dan disiplin kerja terhadap kinerja karyawan PT DEE kantor cabang Jakarta Selatan. Pengumpulan data dilakukan melalui penyebaran kuesioner dan dilaksanakan pada 66 karyawan dari 79 karyawan PT Dagsap Endura Eatore kantor cabang Jakarta Selatan. Analisis data pada penelitian ini menggunakan bantuan SPSS versi 20. Metode analisis data yang digunakan meliputi pengujian data kualitatif dan kuantitatif dengan menggunakan regresi linear berganda yang akan menjelaskan keterkaitan antara variabel terikat dengan variabel bebas. Pengujian yang dilakukan meliputi uji validitas, uji reliabilitas, uji regresi linear berganda, koefisien korelasi, determinasi, uji hipotesis parsial dan hipotesis simultan untuk menguji dan membuktikan hipotesis penelitian. Hasil penelitian menunjukkan bahwa gaya kepemimpinan berpengaruh positif tetapi tidak signifikan terhadap kinerja karyawan. Sedangkan disiplin kerja berpengaruh positif dan signifikan terhadap kinerja karyawan. Secara simultan variabel gaya kepemimpinan dan disiplin kerja berpengaruh positif dan signifikan terhadap kinerja karyawan.
\end{abstract}

Kata kunci: gaya kepemimpinan; disiplin kerja dan kinerja

\section{Pendahuluan}

Dalam semua kegiatan ekonomi yang menjadi faktor utama adalah manusia. Karena manusia merupakan sumber daya yang sangat penting dalam menentukan keberhasilan suatu kegiatan ekonomi tersebut, seperti halnya pada suatu perusahaan. Maka dari itu, manusia lah yang menjadi perencana semua ide dan peraturan-peraturan yang ada dalam perusahaan, serta merupakan tenaga kerja yang menjadi investasi bagi perusahaan dalam meningkatkan produktivitas. Dan semua tindakan yang diambil dalam setiap kegiatan diprakarsai dan ditentukan oleh manusia yang merupakan anggota perusahaan berpotensial, baik pemimpin maupun karyawan untuk mendisiplinkan pola tugas dan pengawasan yang merupakan penentu tercapainya tujuan perusahaan. 
PT Dagsap Endura Eatore (DEE) adalah perusahaan yang bergerak dalam bidang manufaktur olahan makanan. Kinerja karyawan yang tinggi sangat dibutuhkan oleh perusahaan tersebut. Semakin banyak karyawan memiliki kinerja tinggi, maka produktivitas perusahaan secara keseluruhan akan meningkat sehingga perusahaan akan dapat bertahan dalam persaingan global dengan para kompetitor perusahaan. Namun masih banyak karyawan yang kurang bekerjasama dalam pekerjaan dan tidak mentaati peraturan yang sudah ditetapkan seperti contohnya adalah Lead Time. Peraturan Lead Time adalah batas waktu yang ditentukan dalam pemesanan produk setiap harinya terutama bagi para sales yang menerima pesanan dari pelanggan, yang bertujuan untuk membantu para bagian pengiriman dan gudang dalam mempersiapkan barang yang dipesan sampai ke bagian pengiriman, agar lebih mendisiplinkan para karyawan dalam mengurangi resiko yang ditimbulkan. Berdasarkan riset awal PT Dagsap Endura Eatore merupakan perusahaan keluarga, dan hampir semua atasan tertinggi pada perusahaan ini masih memiliki hubungan kerabat satu sama lain, dan terkadang terjadi kesenjangan sosial dalam pelaksanaaan kegiatan perusahaan tersebut seperti contohnya dalam perekrutan karyawan dan pemecahan permasalah dalam kegiatan perusahaan.

Menurut Setiyawan dan Waridin (2006) disiplin sebagai keadaan ideal dalam mendukung pelaksanaan tugas sesuai aturan dalam rangka mendukung optimalisasi kerja. Untuk mewujudkan tujuan perusahaan selain dari fungsi-fungsi manajemen, yang juga perlu diperhatikan adalah gaya kepemimpinan dari seorang pemimpin dalam menjalankan setiap kegiatan perusahaan sesuai dengan bagian-bagiannya masingmasing. Menurut Stuart (2002: 352) bahwa pemimpin adalah seorang yang diharapkan mempunyai kemampuan untuk mempengaruhi, memberi petunjuk dan juga mampu menentukan individu untuk mencapai tujuan organisasi. Dalam suatu perusahaan seorang pemimpin harus bisa bekerjasama pada setiap anggota timnya, agar dapat menjadikan timnya tersebut menjadi solid dan memberikan kinerja optimal demi mewujudkan tujuan perusahaan.

Tujuan penelitian ini adalah untuk mengetahui apakah gaya kepemimpinan dan disiplin kerja (variabel bebas) berpengaruh terhadap kinerja (variabel terikat) karyawan PT DEE. Dan penelitian ini juga diharapkan dapat membantu sebagai bahan literatur dan referensi dalam melakukan penelitian selanjutnya.

\section{Metode Penelitian}

Metode penelitian ini menggunakan metode penelitian kualitatif dan kuantitatif. Metode penelitian kualitatif adalah metode yang menekankan pada aspek pemahaman secara mendalam terhadap suatu masalah dari pada melihat permasalahan untuk penelitian generalisasi. Sedangkan metode penelitian kuantitatif adalah metode yang lebih menekankan pada aspek pengukuran secara obyektif terhadap fenomena sosial, dalam melakukan pengukurannya setiap fenomena sosial dijabarkan ke dalam beberapa komponen masalah, variabel dan indikator.

\section{a. Sumber Sensus}

Data diambil dari karyawan PT Dagsap Endura Eatore kantor Jakarta Selatan. 


\section{b. Metode Observasi}

Menurut Ridwan (2004), metode observasi adalah teknik pengumpulan data, di mana peneliti secara langsung ke objek penelitian untuk melihat dari dekat kegiatan yang dilakukan.

\section{c. Kuesioner}

Kuesioner adalah suatu teknik pengumpulan informasi yang memungkinkan penliti mempelajari sikap-sikap, keyakinan, perilaku dan karakteristik beberapa orang utamanya di dalam organisasi yang bisa terpengaruh oleh sistem yang diajukan atau oleh sistem yang sudah ada.

\section{d. Uji Validitas}

Menurut Ghozali (2005), uji validitas dilakukan untuk menilai seberapa baik suatu instrumen ataupun proses pengukuran terhadap konsep yang diharapkan untuk mengetahui apakah kita tanyakan dalam kuesioner sudah sesuai dengan konsepnya. Suatu kuesioner dapat dikatakan valid atau tidak dengan membandingkan antara $r$ hitung dengan $r$ tabel. Di mana jika $r$ hitung $>r$ tabel atau $t$ signifikan $<\alpha=0,05$ maka instrumen tersebut dapat dikatakan valid. Dan sebaliknya, apabila $r$ hitung $<r$ tabel atau $\mathrm{t}$ signifikan $>\alpha=0,05$

\section{e. Regresi Linier Berganda dan Koefisien Korelasi}

Analisis regresi digunakan untuk menguji hipotesis tentang pengaruh variabel bebas (independent) terhadap variabel terikat (dependet), berhubungan positif atau negative dan untuk memprediksi nilai dari variabel terikat apabila variabel bebas mengalami kenaikan atau penurunan.

Keterangan:

$$
\begin{array}{ll}
\mathrm{Y} & =\text { Kinerja Karyawan } \\
\mathrm{X} 1 & =\text { Gaya Kepemimpinan } \\
\mathrm{X} 2 & =\text { Disiplin Kerja } \\
\mathrm{a} & =\text { nilai Constant } \\
\beta 1 \& 2 & =\text { Koefisien }
\end{array}
$$

\section{f. Koefisien Determinasi $\left(\mathbf{R}^{\mathbf{2}}\right)$}

Koefisien determinasi merupakan besaran yang menunjukkan besarnya variasi variabel dependen yang dapat dijelaskan oleh variabel independennya. Dengan kata lain, koefisien determinasi ini digunakan untuk mengukur seberapa jauh variabelvariabel bebas (independen) dalam menerangkan variabel terikatnya (dependen).

\section{g. Uji Hipotesis Parsial (Uji t)}

Uji t digunakan untuk menguji secara parsial masing-masing variabel. Hasil uji $t$ dapat dilihat pada tabel coefficients pada kolom sig (significance). Jika probabilitas nilai t atau signifikansi $<0,05$, maka dapat dikatakan bahwa terdapat pengaruh antara variabel bebas terhadap variabel terikat secara parsial. 
Namun, jika probabilitas nilai t atau signifikansi > 0,05, maka dapat dikatakan bahwa tidak terdapat pengaruh yang signifikan antara masing-masing variabel bebas terhadap variabel terikat.

\section{h. Uji Simultan (Uji F)}

Uji $\mathrm{F}$ digunakan untuk mengetahui pengaruh variabel bebas secara bersama-sama (simultan) terhadap variabel terikat. Signifikan berarti hubungan yang terjadi dapat berlaku untuk populasi.

\section{i. Wawancara}

Wawancara adalah salah satu metode pengumpulan data untuk mendapatkan informasi dengan cara langsung kepada responden.

\section{j. Lokasi}

Penelitian dilakukan di kantor PT Dagsap Endura Eatore yang berlokasi di Perkantoran Grand Wijaya Center, Jl Wijaya II Blok F No 83B Kebayoran Baru, Jakarta Selatan.

\section{Hasil Dan Pembahasan}

\section{Uji Validitas}

Tabel 1 Uji Validitas

\begin{tabular}{|l|r|c|c|}
\hline \multicolumn{1}{|c|}{ Pernyataan Variabel } & r hitung & r tabel & Keterangan \\
\hline Gaya kepemimpinan 1 & 0.412 & 0,2042 & Valid \\
Gaya kepemimpinan 2 & 0.478 & 0,2042 & Valid \\
Gaya kepemimpinan 3 & 0.453 & 0,2042 & Valid \\
Gaya kepemimpinan 4 & 0.408 & 0,2042 & Valid \\
Gaya kepemimpinan 5 & 0.572 & 0,2042 & Valid \\
Gaya kepemimpinan 6 & 0.485 & 0,2042 & Valid \\
Gaya kepemimpinan 7 & 0.269 & 0,2042 & Valid \\
\hline Disiplin Kerja 1 & 0.518 & 0,2042 & Valid \\
Disiplin Kerja 2 & 0.373 & 0,2042 & Valid \\
Disiplin Kerja 3 & 0.380 & 0,2042 & Valid \\
Disiplin Kerja 4 & 0.279 & 0,2042 & Valid \\
Disiplin Kerja 5 & 0.285 & 0,2042 & Valid \\
\hline Kinerja 1 & 0.467 & 0,2042 & Valid \\
Kinerja 2 & 0.424 & 0,2042 & Valid \\
Kinerja 3 & 0.576 & 0,2042 & Valid \\
Kinerja 4 & 0.428 & 0,2042 & Valid \\
Kinerja 5 & 0.543 & 0,2042 & Valid \\
\hline
\end{tabular}

Dari tabel 1 terlihat bahwa korelasi antara masing-masing indikator terhadap total skor konstruk dari setiap variabel menunjukkan hasil yang signifikan, dan menunjukkan bahwa $r$ hitung $>r$ tabel. Sehingga dapat disimpulkan bahwa semua item pernyataan dinyatakan valid.

\section{Regresi Linier Berganda dan Koefisien Korelasi}

Tabel 2 Rgeresi Linier Berganda dan Koefisien Korelasi

\begin{tabular}{|c|c|c|c|c|}
\hline & \multirow[t]{2}{*}{ Model } & \multicolumn{2}{|c|}{$\begin{array}{c}\text { Unstandardized } \\
\text { Coefficients }\end{array}$} & \multirow[t]{2}{*}{ Sig. } \\
\hline & & $\mathrm{B}$ & Std. Error & \\
\hline \multirow{3}{*}{1} & (Constant) & 8.682 & 2.320 & .000 \\
\hline & $\begin{array}{l}\text { Gaya } \\
\text { Kepemimpinan }\end{array}$ & .034 & .080 & .676 \\
\hline & Disiplin Kerja & .461 & .127 & .001 \\
\hline
\end{tabular}




$$
Y=a+\beta_{1} X_{1}+\beta_{2} X_{2}
$$

Hasil dari penelitian ini adalah:

$$
\mathrm{Y}=\mathbf{8 , 6 8 2}+\mathbf{0 , 0 3 4} \mathrm{X} 1+\mathbf{0 , 4 6 1} \mathrm{X} 2
$$

Keterangan:

$$
\begin{aligned}
& \mathrm{Y} \text { = Kinerja Karyawan } \\
& \mathrm{X} 1=\text { Gaya Kepemimpinan } \\
& \text { X2 = Disiplin Kerja } \\
& \text { a }=\text { nilai Constant } \\
& \beta 1 \& 2=\text { Koefisien }
\end{aligned}
$$

Dari persamaan di atas dapat dijabarkan:

a. Gaya kepemimpinan dan disiplin kerja mempunyai koefisien korelasi (dilihat dari Standardize Coefficients pada Beta) sebesar 0.049 yang bertanda positif, yang menunjukkan bahwa hubungan antara variabel gaya kepemimpinan dan disiplin kerja (variabel bebas) terhadap kinerja karyawan (variabel terikat) adalah positif.

b. Koefisien gaya kepemimpinan memberikan nilai sebesar 0,034 yang berarti bahwa jika gaya kepemimpinan semakin baik maka kinerja karyawan akan mengalami peningkatan. Begitu pula sebaliknya apabila gaya kepemimpinan kurang baik maka kinerja karyawan akan mengalami penurunan.

c. Koefisien disiplin kerja memberikan nilai sebesar 0,461 yang brarti bahwa jika disiplin kerja semakin baik maka kinerja karyawan akan mengalami peningkatan. Begitu pula sebaliknya apabila displin kerja kurang baik maka akan berdampak pada kinerja karyawan yang mengalami penurunan.

\section{Koefisien Determinasi $\left(\mathbf{R}^{2}\right)$}

\begin{tabular}{|c|c|c|c|}
\hline Model & $\mathrm{R}$ & R Square & Adjusted R Square \\
\hline 1 & $.438^{\mathrm{a}}$ & .192 & .166 \\
\hline
\end{tabular}

Koefisien determinasi merupakan besaran yang menunjukkan besarnya variasi variabel dependen yang dapat dijelaskan oleh variabel independennya. Dengan kata lain, oefisien determinasi ini digunakan untuk mengukur seberapa jauh variabelvariabel bebas (independen) dalam menerangkan variabel terikatnya (dependen). Nilai koefisien determinasi ditentukan dengan nilai adjusted $\mathrm{R}$ square yaitu sebagai berikut:

Hasil perhitungan regresi dapat diketahui bahwa koefisien determinasi (adjusted $R^{2}$ ) yang diperoleh adalah sebesar 0,166. Dalam hal ini berarti 16,6\% variasi variabel kinerja karyawan dapat dijelaskan oleh variabel gaya kepemimpinan dan disiplin kerja, sedangkan sisanya sebesar 83,4\% diterangkan oleh variabel lain yang tidak ada dalam penelitian ini. 


\section{Uji Hipotesis Parsial (Uji t)}

Uji t digunakan untuk menguji secara parsial masing-masing variabel. Hasil uji t dapat dilihat pada tabel coefficients pada kolom sig (significance). Jika probabilitas nilai $\mathrm{t}$ atau signifikansi $<0,05$, maka dapat dikatakan bahwa terdapat pengaruh antara variabel bebas terhadap variabel terikat secara parsial.

Namun, jika probabilitas nilai $\mathrm{t}$ atau signifikansi $>0,05$, maka dapat dikatakan bahwa tidak terdapat pengaruh yang signifikan antara masing-masing variabel bebas terhadap variabel terikat.

\section{Tabel 4 Uji Hipotesis Parsial (Uji t)}

\begin{tabular}{|c|c|c|c|}
\hline & Variabel independen & t hitung & t. Sig. \\
\hline \multirow{3}{*}{1} & (Constant) & 3.742 & .000 \\
\hline & $\begin{array}{l}\text { Gaya } \\
\text { Kepemimpinan }\end{array}$ & .419 & .676 \\
\hline & Disiplin Kerja & 3.631 & .001 \\
\hline
\end{tabular}

a. Hasil pengujian hipotesis gaya kepemimpinan memiliki nilai t hitung sebesar 0,419 dengan signifikansi sebesar 0,676, serta t tabel sebesar 1,669. Dengan nilai signifikan tersebut $0,676>0,05$, dan $\mathrm{t}$ hitung $0,419<\mathrm{t}$ tabel 1,669 maka akan ditarik kesimpulan bahwa Ha untuk gaya kepemimpinan ditolak dan Ho gaya kepemimpinan diterima. Dengan demikian dapat disimpulkan bahwa hipotesis H1 "Gaya kepemimpinan tidak berpengaruh signifikan terhadap kinerja karyawan PT DEE kantor Jakarta Selatan"

b. Hasil pengujian hipotesis disiplin kerja memiliki nilai t hitung sebesar 3,631 dengan nilai signifikan sebesar 0,001, dan t tabel 1.669. Dengan nilai signifikan tersebut sebesar $0,001<0,05$, dan nilai t hitung sebesar 3.631 > t tabel 1,669 yang berarti bahwa Ha untuk disiplin kerja diterima dan Ho disiplin kerja ditolak. Dengan demikian dapat ditarik kesimpulan bahwa hipotesis H2 "Disiplin kerja berpengaruh signifikan dan positif terhadap kinerja karyawan PT DEE kantor Jakarta Selatan".

\section{Uji Simultan (Uji F)}

Uji F digunakan untuk mengetahui pengaruh variabel bebas secara bersamasama terhadap variable terikatnya (simultan).

\begin{tabular}{|c|c|c|c|}
\hline Model & & $\mathrm{F}$ & Sig. \\
\hline \multirow{3}{*}{1} & Regression & 7.478 & $.001^{\mathrm{b}}$ \\
\hline & Residual & & \\
\hline & Total & & \\
\hline
\end{tabular}

Sumber: Data primer diolah, 2015.

Hasil pengujian hipotesis yang dilakukan bersamaan oleh variabel gaya kepemimpinan dan disiplin kerja menunjukkan nilai signifikan sebesar 0,001. Dengan signifikan tersebut lebih kecil dari 0,05, yang berarti bahwa Ha untuk gaya kepemimpinan dan disiplin kerja yang dilakukan bersamaan yaitu diterima dan Ho gaya kepemimpinan dan disiplin kerja ditolak. Dengan demikian dapat berarti bahwa 
hipotesis H3 "Gaya kepemimpinan dan disiplin kerja mempunyai pengaruh signifikan terhadap kinerja karyawan PT DEE kantor Jakarta Selatan”.

\section{Wawancara}

Wawancara adalah salah satu metode pengumpulan data untuk mendapatkan informasi dengan cara langsung kepada responden. Dalam penelitian ini wawancara merupakan metode penelitian tambahan, dikarenakan pada uji hipotesis parsial untuk variabel gaya kepemimpinan tidak berpengaruh signifikan terhadap kinerja karyawan, dan juga mengenai uji koefiesien determinasi menunjukkan bahwa 16,6\% variasi variabel kinerja karyawan dapat dijelaskan oleh variabel gaya kepemimpinan dan disiplin kerja, sedangkan sisanya sebesar 83,4\% diterangkan oleh variabel lain yang tidak ada dalam penelitian ini. Hasil wawancara informal terhadap beberapa responden yang dilakukan peneliti mengenai varibel atau faktor lain yang menyebabkan kinerja mereka menurun atau meningkat adalah:
a. Lingkungan kerja
b. Gaji (salary)
c. Insentif (rewards)

\section{Kesimpulan}

Berdasarkan pada hasil data analisis dapat diberi kesimpulan adalah sebagai berikut:

1. Tidak adanya pengaruh signifikan antara gaya kepemimpinan terhadap kinerja karyawan PT Dagsap Endura Eatore kantor pemasaran cabang Jakarta Selatan. Berdasarkan interview nonformal kepada para responden, terdapat beberapa faktor lain yang dapat mempengaruhi kinerja mereka. Pertama yaitu faktor lingkungan kerja dalam perusahaan, dengan suasana kekeluargaan. Dan yang kedua yaitu faktor gaji atau salary. Dan yang terakhir adalah faktor insentif atau rewards.

2. Adanya pengaruh positif dan signifikan antara disiplin kerja terhadap kinerja karyawan PT Dagsap Endura Eatore kantor pemasaran cabang Jakarta Selatan. Berdasarkan kesimpulan ini dalam kegiatan perusahaan menerapkan peraturan untuk mendisiplinkan karyawannya.

3. Adanya pengaruh positif dan signifikan antara gaya kepemimpinan dan disiplin kerja yang dilakukan bersamaan terhadap kinerja karyawan PT Dagsap Endura Eatore kantor pemasaran cabang Jakarta Selatan. 


\section{DAFTAR PUSTAKA}

Bacal, Robert. Performance Management. Terjemahan Surya Dharma, Yanuar Irawan, (Jakarta: Gramedia Pustaka Utama).

Handoko, T. Hani. (2000). Manajemen Personalia dan Sumber Daya Manusia. Yogyakarta: BPFE Universitas Gajah Mada.

Hendriawan. (2014). Pengaruh Gaya Kepemimpinan dan Budaya Organisasi terhadap Kinerja Karyawan Pada PT Dwimitra Multiguna Sejahtera di Kabupaten Konawe Utara Provinsi Sulawesi Tenggara. Makassar: Universitas Hasanudin.

Herianty, Dewita. (2007). Analisis Pengaruh Budaya Organisasi, Kepuasan Kerja, dan Gaya Kepemimpinan terhadap Kinerja Karyawan dengan Komitmen Organisasi Sebagai Variabel Intervening. (Tesis Pasca Sarjana Universitas Diponogoro Semarang).

Mangkunegara, A.A. Anwar Prabu. (2001). Manajemen Sumber Daya Manusia. (Bandung: PT Rosdakarya).

Malthis, R.L dan Jackson. (2001). Manajemen Sumber Daya Manusia. (Jakarta: Salemba Empat).

Reza, Regina Aditya. (2010). Pengaruh Gaya Kepemimpinan, Motivasi, dan Disiplin Kerja terhadap Kinerja Karyawan PT Sinar Santosa Perkasa Banjarnegara. (Semarang: Universitas Diponegoro).

Rivai, Veithzal, dan Ahmad Fawzi Mohd. Basri. (2005). Performance Appraisal: Sistem Yang Tepat Menilai Kinerja Karyawan dan Meningkatkan Daya Saing Perusahaan, (Jakarta: Rajawali Pers).

Robbins, Stephen. P. (2006). Perilaku Organisasi. Edisi Bahasa Indonesia. (Jakarta: PT. Indeks Kelompok Gramedia, 2006).

Siagian, Sondong. P. (2002). Kiat Meningkatkan Produktivitas Kerja. (Jakarta: PT Rineka Cipta).

Simamora, Henry. (2004). Manajemen Sumber Daya Manusia, (Yogyakarta: STIE YKPN).

Sinambela, Lijan Poltak. (2012). Kinerja Pegawai, Teori Pengukuran dan Implikasi (Yogyakarta: Graha Ilmu).

Tika, P. (2006). Budaya Organisasi Dan Peningkatan Kinerja Perusahaan. (Jakarta: PT. Bumi Aksara). 
Ummah, Annisatul. (2011). Pengaruh Komitmen Organisasi, Gaya Kepemimpinan, Stres Kerja dan Motivasi terhadap Kinerja Auditor. (Skripsi Mahasiswa Universitas Syarif Hidayatullah).

Ghozali, Imam. (2005). Structural Equation Modeling: Teori, Konsep, dan Aplikasi dengan Program Lisrel 8.54. (Semarang: Badan Penerbit Universitas Diponegoro,). 